\title{
Saúde e Educação: a discussão das relações de poder na atenção à saúde da mulher
}

\author{
Ana Flávia P. Lucas d'Oliveira ${ }^{1}$
}

D'OLIVEIRA, A. F. L. Health care and education: a discussion of power in women's health care. Interface Comunicação, Saúde, Educação, v.3, n.4, 1999.

This paper discusses issues that surround educational actions in the health field, based on the proposal included in the materials from the PAISM - Programa de Atenção Integral à Saúde da Mulher (Complete Attention to Women's Health Program), published during the eighties, which was developed and implemented with substantial articipation of the feminist movement. The advances brought about by the participation of the social movement in the development and implementation of health policies are discussed, as well as those impasses in providing assistance that resulted from participation. The conclusion reached is that the program did not fail to confront and to indicate risks and possibilities in the integration of the question of power within health-care services, whether through reference to male-female issues in society, or whether through reference to the relationship between health care and women, raising important ethical and political issues with regard to the internal operation of the services. The potential technical interpretation of this matter - a possibility given both socially and historically - revealed itself, however, pretermitted by conflicts and dilemmas, from the ethical and political to the scientific and technological, such as the difficulty in balancing quality and quantity, technical knowledge and folk wisdom, as well as in questioning the power relations within institutions acknowledged by society to hold great technical and moral authority.

KEY WORDS: women's health, community health service, health education.

Busca-se discutir algumas questões acerca das ações educativas em saúde a partir da proposta contida no material do Programa de Atenção Integral à Saúde da Mulher (PAISM), publicado na década de 80 e elaborado $e$ implementado com importante participação do movimento feminista. Abordam-se os avanços trazidos pela participação do movimento social na elaboração e implantação de políticas de saúde, ao lado dos impasses assistenciais que esta mesma participação acaba por colocar. Conclui-se que o programa não deixou de enfrentar riscos e possibilidades na incorporação das questões do poder, seja por referência às questões homem-mulher na sociedade, seja por referência às relações medicina-mulheres, no interior dos serviços de saúde, trazendo uma importante questão ético-política para o interior dos serviços.

A possível tradução técnica dessa questão - possibilidade histórica e socialmente dada - mostrou-se, contudo, perpassada por conflitos e dilemas entre o ético-político e o científico-tecnológico, como a dificuldade de compor qualidade e quantidade, saber técnico e saber popular e de questionar as relações de poder no interior de instituições de grande autoridade técnica e moral na sociedade.

PALAVRAS-CHAVE: saúde da mulher, serviços de saúde comunitária, educação em saúde.

\footnotetext{
${ }^{1}$ Doutoranda em Medicina Preventiva da Faculdade de Medicina da Universidade de São Paulo/USP/SP. E-mail: afolive@usp.br
} 


\begin{abstract}
"Como feministas nos oponemos totalmente al sistema médico por su condicion de fuente de ideologia sexista. Pero al mesmo tiempo dependemos totalmente de la tecnologia médica para acceder a las más básicas y elementales libertades que precisamos como mujeres: libertad de los embarazos no deseados, libertad de las dolências físicas crónicas. Puede repugnarnos el descarado sexismo de algunos médicos y puede enfurecernos el sexismo sofisticado que nos quieren hacer pasar como teoria médica, pero son nuestra unica possibilidad de conseguir abortos, diafragmas, antibióticos e intervenciones quirúrgicas essenciales"

(Ehrenreich \& English, 1981, p. 81).
\end{abstract}

No início dos anos 80 o Ministério da Saúde lança, no Brasil, uma proposta de atenção que até hoje é referência para o movimento de mulheres e para responsáveis pela implantação de políticas públicas na área de saúde da mulher, o Programa de Atenção Integral à Saúde da Mulher (PAISM).

Diversas correntes de saber e práticas sociais têm influência na formulação do PAISM, especialmente nos aspectos aqui analisados: o chamado movimento sanitário, que tem como expressão institucional a proposta da Reforma Sanitária, e o feminismo, mais visível na proposta educativa que permeia os documentos do programa. Formulado por uma articulação entre feministas e/ou sanitaristas, o PAISM deu ênfase aos cuidados básicos de saúde, e talvez por isto as "ações educativas" se destacam na proposta. Procuramos aqui analisar alguns aspectos do Programa sob o foco de sua dimensão educativa, que traz a maior novidade e a marca diferencial deste em relação a outros programas: a politização, pela tentativa ousada de incluir a discussão acerca das relações de poder no interior dos serviços de saúde, possibilitada pela inclusão do movimento social, representando os interesses dos "sujeitos" (participantes $e$ submetidos aos) programas, que chegam tematizando as relações de gênero, classe e etnia. A ilustração a seguir, que faz parte de uma série de cartilhas intituladas "Esse sexo que é nosso", produzidas pela Fundação Carlos Chagas como material educativo a ser utilizado nos serviços de saúde pelo PAISM (Esse sexo que é nosso, 1990) demonstra de forma clara esta pretensão:

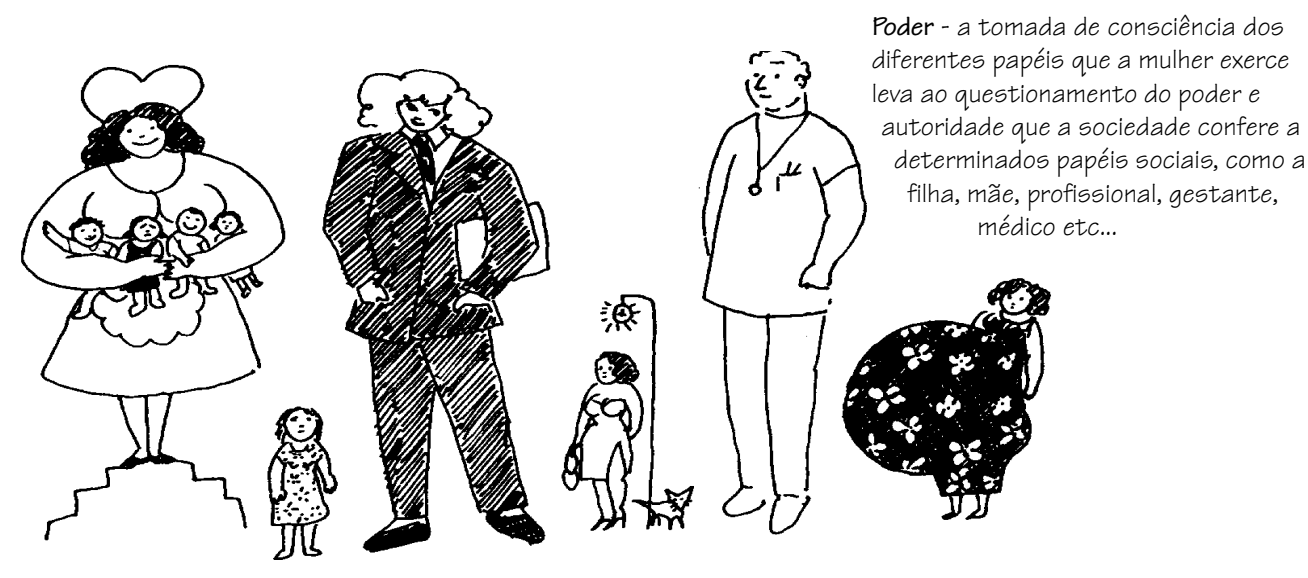

106 Interface - Comunic, Saúde, Educ 4 
Compartilhar - recuperar o próprio poder de autoridade sobre si mesma é um dos efeitos de pertencer a um grupo no qual sua fala é ouvida e respeitada e onde se pode interagir, compreender e compartilhar histórias de outras mulheres.
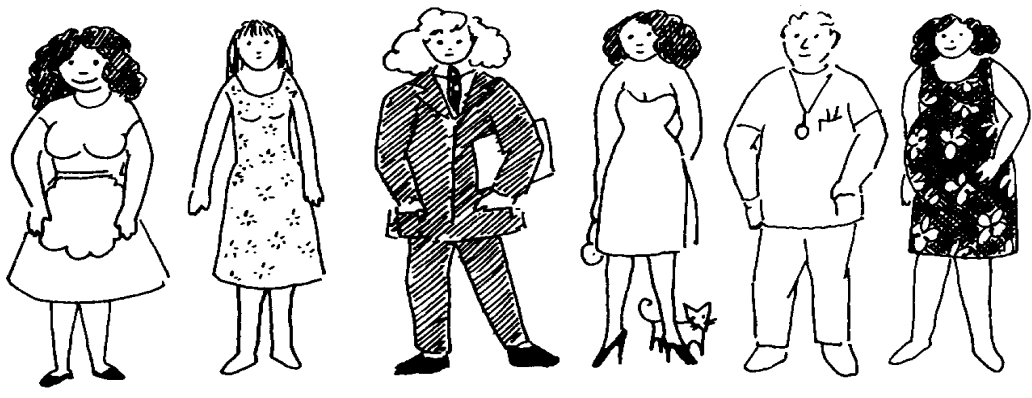

A politização, que chama atenção no PAISM por sua força, está hoje bem incorporada nas ações de saúde pensadas em termos coletivos, como o demonstram mais evidentemente o caso da luta contra a AIDS e a área de saúde mental.

Trabalhamos aqui algumas idéias que fazem parte da dissertação de mestrado na qual o Programa é apresentado de forma mais ampla (d'Oliveira, 1996). As ilustrações são parte do material educativo consultado, e algumas são trazidas aqui a título de exemplo. Nunca é demais lembrar que trabalhamos com as potencialidades abertas da proposta tal como foi formulada, e não estamos fazendo a análise da implantação do PAISM, mas sim levantando questões acerca das possibilidades expressas nos documentos oficiais. Sabemos da existência de múltiplos PAISMs concretos pelo país, e dedicamos este texto a todas as pessoas que batalham cotidianamente nesta construção. Oxalá ele possa contribuir de alguma forma para esta prática cotidiana cheia de riscos, conquistas, decepções $e$ questionamentos.

\section{Os antecedentes}

No final da década de 70 o feminismo brasileiro floresce e apropria-se de experiências do feminismo internacional, criando diversos grupos $e$ instituições não governamentais que trabalhavam na área da saúde, alguns inclusive realizando atendimento em clínicas feministas. Por outro lado, um amplo movimento popular de bairro, com grande expressão na saúde, é composto principalmente por mulheres, com maior ou menor influência de idéias feministas.

No debate populacional então vigente, o feminismo coloca uma nova posição alternativa tanto ao "natalismo" quanto ao "controlismo", passando a conceber, no início dos anos 80, o exercício dos direitos reprodutivos como condição de cidadania, enfatizando a responsabilidade social na extensão destes direitos $e$ a necessidade de uma atenção ampla à saúde reprodutiva como essencial a essa extensão (Corrêa, 1993). As mulheres 
pediam o direito à autonomia como indivíduos sociais e à escolha individual contextualizada. A noção norte-americana de direito ao próprio corpo é relida na América Latina em um novo marco de direitos, que busca afastarse da concepção liberal $e$ individualista e pretende entender esses direitos como também imediatamente sociais. Mais recentemente, este mesmo movimento abriu espaço e colocou a necessidade de estudo e questionamento, também, da experiência masculina com a reprodução $e$ a sexualidade, o que deve enriquecer e complexificar ainda mais esta questão.

Se a contracepção era reconhecida como uma necessidade para as mulheres brasileiras, as condições em que a opção contraceptiva era realizada deixavam muito a desejar. A noção de que o direito à escolha de ter ou não filhos estava contextualizado em uma ampla rede de direitos sociais, tanto no espaço público como privado, e que envolvia a educação, a sexualidade, a gravidez indesejada $e$ o aborto, a qualidade da assistência gineco-obstétrica, a divisão social e sexual do trabalho, e o apoio social à maternidade, fez com que as questões de contracepção se recolocassem neste marco ampliado de direitos reprodutivos e sexuais (Corrêa $\mathcal{E}$ Petchesky, 1994). As feministas viriam propor, entretanto, uma nova visão da integralidade: a integralidade do sujeito mulher, que deve ser encarada como indivíduo e sujeito de direitos e percebida como uma totalidade, e não reduzida a um corpo reprodutivo, individual ou populacional. Em um mesmo movimento, as mulheres pediam a democratização do saber médico $e$ a consideração do saber das mulheres, questionando, internamente, o poder dos serviços de saúde. (Labra, 1989) e, ao mesmo tempo, reivindicavam o direito ao acesso universal à saúde $e$ aos cuidados médicos.

Por outro lado, em 1986, a VIII Conferência Nacional de Saúde (CNS) coroaria um amplo processo de mobilização nacional, levado a cabo na primeira metade dos anos 80 , que consagraria os princípios de um "verdadeiro programa de implantação da Reforma Sanitária". A institucionalização dessa proposta consubstanciou-se mais tarde na proposta do Sistema único de Saúde (SUS) (Teixeira, 1989).

O PAISM surge neste mesmo movimento e sua implantação exigia uma rede de serviços de saúde com acesso universal, hierarquizada e regionalizada, que prestasse ações de controle de doenças e riscos de adoecimento, em um momento em que a rede de serviços de saúde pública incorporavam definitivamente a assistência médica individual a doentes como sua atividade principal.

Note-se que na composição destas duas fontes (Feminismo e Reforma Sanitária), das quais se alimentaria o PAISM, há uma tensão. Entre os critérios médico-sanitários, por um lado, e a consideração do saber das mulheres e o resgate de sua condição de sujeito, por outro, existe complementariedade, mas também contradição. A priorização, elemento essencial para a proposta médico-sanitária, e a integralidade, ponto básico do feminismo, tinham em comum o estímulo à ampliação da cobertura assistencial, mas com lógicas diversas. Enquanto as mulheres pediam o acesso ampliado a serviços com nova qualidade e renovadas relações de poder, a Reforma Sanitária pensava em um acesso ampliado com racionalização das ações do ponto de vista médico sanitário, o que 
implicaria, em tese, em priorização, com escolhas baseadas sobretudo no saber médico.

Como garantir a universalidade e integralidade em um contexto de racionamento de recursos e acelerada medicalização, com custos e ofertas cada vez maiores, que virtualmente impossibilitam o acesso de todas a tudo e colocam a necessidade de priorização? E como garantir a democratização do poder no interior de instituições com tradição de exercício de poder de forma bastante autoritária e grande legitimidade social neste exercício? São dilemas da organização de serviços de saúde que o PAISM recoloca com agudeza.

\section{O PAISM}

Em 1983, foram elaboradas, por um grupo que reunia sanitaristas, pesquisadores, feministas e representantes do Ministério da Saúde, as bases programáticas do Programa de Atenção Integral à Saúde da Mulher (PAISM). Pela primeira vez um programa dirigido às mulheres tinha as próprias mulheres organizadas como interlocutoras privilegiadas, interferindo no seu planejamento, implantação e fiscalização.

O Programa da Atenção à Saúde da Mulher (PAISM), lançado em 1984, tem como documento base o texto: "Assistência Integral à Saúde da Mulher: bases de ação programática". O primeiro parágrafo já deixa clara a intenção do PAISM de realizar uma importante mudança na maneira de apreender a mulher, por referência à política de saúde já tradicional nesta área:

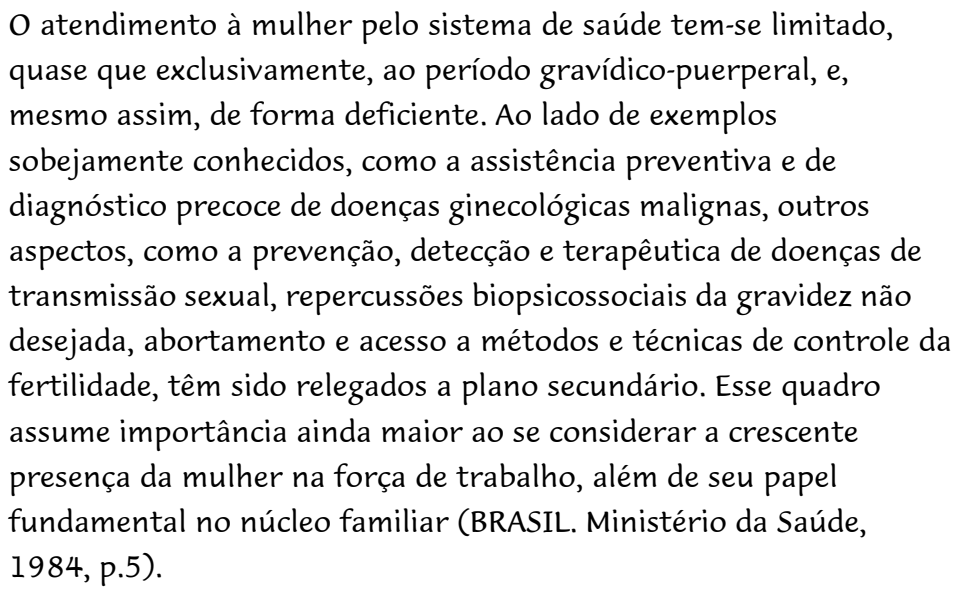

A crescente presença da mulher no mercado de trabalho $e$ a urbanização do país, mudavam gradativamente o padrão de família e geravam novas necessidades em relação aos programas de saúde dirigidos à mulher.

$O$ apoio do movimento feminista ao PAISM não foi unânime nem imediato. Visivelmente incomodado com a situação de ter seus desejos atendidos por um governo militar e autoritário, (Gen. Figueiredo) o movimento dividiu-se entre acusar mais uma vez o Programa de controlista, desconfiado da oferta contraceptiva enfim assumida pelo Estado, ou engajarse em sua implantação, tentando garantir a contextualização desta oferta no 
sentido dos "direitos reprodutivos" . A parte mais expressiva do movimento parece ter aderido a esta última opção, entendendo-a como uma possibilidade de interferir mais efetivamente nos rumos das políticas públicas destinadas à saúde da mulher.

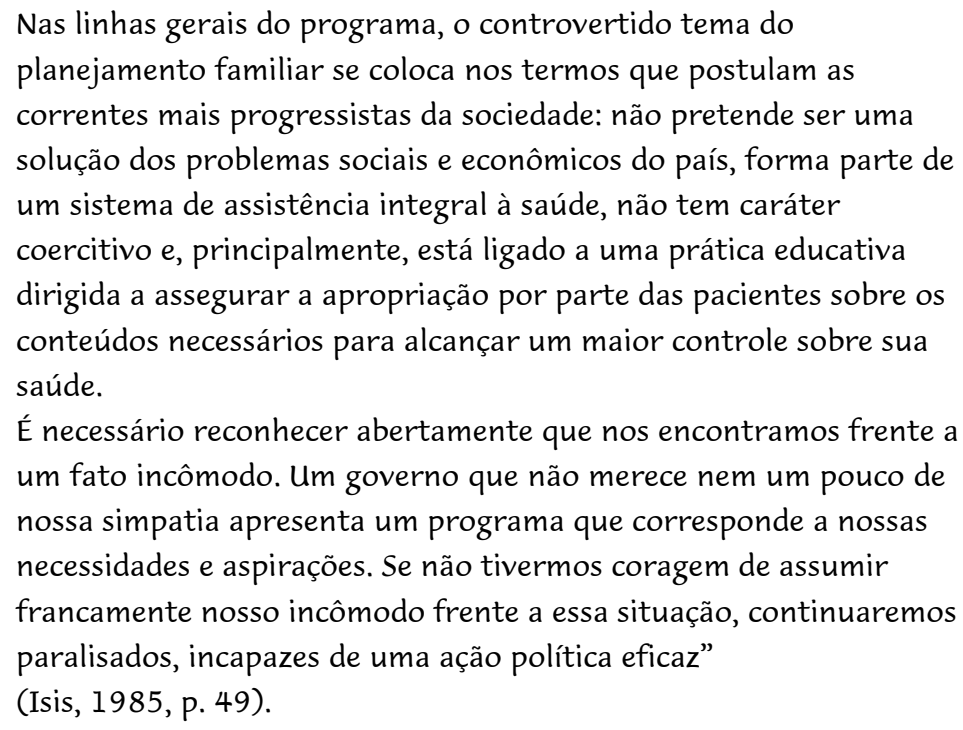

Bem recebido por amplos setores da sociedade, o PAISM passa a constituir o modelo assistencial tido como capaz de atender às necessidades globais da saúde feminina. Incorpora, além da tradicional assistência ao prénatal, parto e puerpério, a detecção precoce de neoplasias de mama e colo de útero, a detecção, o tratamento e a prevenção de doenças sexualmente transmissíveis, a contracepção $e$ a atenção à esterilidade, a assistência à adolescente e à mulher idosa, a prevenção da gravidez indesejada, a educação em todas as ações dirigidas à mulher e o cuidado à saúde da mulher trabalhadora e às patologias clínicas mais comuns. Todas essas ações deveriam estar integradas e ser oferecidas a cada contato da mulher com o serviço.

Além de ampliar quantitativamente, o PAISM tinha o potencial de alterar também qualitativamente o trabalho realizado. Pensado enquanto estratégia de implantação de uma racionalização da organização de serviços, o PAISM foi pensado também como programa de saúde que buscava reorientar o trabalho médico e de toda a equipe de saúde. Assim, o PAISM constitui um modelo tecnológico de trabalho que busca ampliar a cobertura com uma nova qualidade no trabalho, racionalizando-o no sentido de um maior impacto nas condições de saúde e incorporando a dimensão educativa na assistência.

Os conteúdos programáticos listados no documento intitulado "Assistência integral à saúde da mulher: bases de ação programática" (BRASIL, 1984) estão distribuídos em três atividades nucleares do PAISM: a assistência clínica ginecológica, a assistência pré-natal e a assistência ao parto e puerpério imediato. Nessas atividades, os conteúdos mesclam ações clínicas, educativas e de controle de riscos ou detecção precoce de doenças. 
Observando as atividades e o conteúdo da assistência pretendida pelo PAISM fica evidente que ele mantém nas atividades propostas o recorte da mulher como corpo reprodutivo. Entretanto, a proposta busca ampliar esse recorte em várias direções. Além da mulher-mãe, a mulher-sexual, de qualquer idade, passa a ser também alvo das ações do serviço de saúde, quando se estimula o planejamento familiar, o controle do câncer ginecológico e das doenças sexualmente transmissíveis. A atenção para as adolescentes e idosas amplia essa atenção para além da idade fértil. Todas essas ações buscam, ainda, absorver e ampliar as questões relativas à reprodução e sexualidade para além da dimensão puramente biológica, incorporando a vida social na abordagem dessas questões. Por último, a idéia de sujeito integral, bio-psicosocial, exigiria uma atenção também para além da reprodução e da sexualidade, abrangendo a saúde mental, a saúde no trabalho e as patologias clínicas mais prevalentes, bem menos desenvolvidas.

O PAISM teve, pois, como objeto, uma mulher reprodutiva e sexual, assumindo a especificidade feminina tal como foi historicamente constituída, mas localiza essa diferença mais uma vez, como há mais de um século, no aparelho reprodutivo sexual do corpo humano. Assim, ainda que não abandone seus pressupostos de origem, mas busque também a construção social dessa diferença, procurando tecnologias inovadoras, o PAISM acata a priorização dos aspectos reprodutivos e sexuais da saúde feminina, o que expressa uma realidade. As relações de gênero, tais como atualmente constituídas, colocam para as mulheres inúmeras necessidades de saúde reprodutiva e sexual que não podem ser desconsideradas.

Complementarmente, e talvez ainda mais importante, o trabalho em saúde dirigido às mulheres tradicionalmente oferece respostas a necessidades recortadas como reprodução biológica. Essa demanda, assim estabelecida, é como já vimos ponto crucial da crítica feminista e de amplos setores da área da saúde.

Em novembro de 1984 ocorreu o $1^{\circ}$ Encontro Nacional de Saúde da Mulher, um marco na área. As mulheres presentes, feministas $e$ trabalhadoras da saúde, definiam, no documento final do encontro, que ficou conhecido como Carta de Itapecirica:

\footnotetext{
O papel sexual e reprodutor imposto à mulher pela sociedade, que a exclui das decisões sobre o seu próprio corpo, faz com que

A especificidade sexual leva as mulheres a procurar uma prática médica 
que repõe o papel sexual e reprodutor que esta mesma prática e muitas outras a ela articuladas criaram. Ao mesmo tempo, ao estender a demanda por assistência, as mulheres reivindicam a extensão da medicalização, tanto em seu aspecto positivo de extensão de direitos de consumo de serviços $e$ tecnologias eficazes como no sentido negativo de renúncia ao juízo privado, alvo das críticas das próprias mulheres aos serviços. Dilema inscrito no interior do próprio programa, o PAISM não pára de refletir sobre si próprio, transformando a prática médica $e$ as mulheres e correndo os riscos inerentes à abertura de novos papéis sexuais, reprodutores e assistenciais.

A partir de 1985 inicia-se a publicação de numeroso e variado material destinado a regulamentar e operacionalizar as ações propostas, agora com mais detalhes.

Esse material é composto por dois grandes conjuntos de documentos: o primeiro consiste de diversas normas e manuais técnicos (assistência prénatal de baixo e alto risco, ao parto, puerpério e recém-nascido, controle do câncer cérvico-uterino e mamas, planejamento familiar e doenças sexualmente transmissíveis), e o segundo em um extenso material educativo.

No conjunto denominado "Normas e Manuais Técnicos" existe uma detalhada padronização de cada atividade, normatizando ações de orientação clínica e/ou epidemiológica. A dimensão educativa está presente aqui geralmente para lembrar da importância de algum exame ou consulta de rotina ou seguimento, ou para recomendar determinadas atitudes (aleitamento materno, por exemplo), ou ainda como lembrança da necessidade de explicar o que se faz, passar informações e escutar a mulher.

Percebe-se aqui o cuidado de colocar conteúdos educativos a respeito do auto-cuidado e a inclusão, em todas as atividades, da busca de um maior vínculo e aderência das usuárias às diversas atividades oferecidas, muitas delas de detecção precoce e controle de riscos.

Cada contato da mulher com o serviço de saúde deve servir para que ela seja lembrada de alguma outra eventual necessidade sua, ou de que ela deva retornar para o seguimento em alguma outra ação. A educação tem um papel fundamental nessa reiteração. Se essas ações continuam sendo cruciais para evitar mortes e adoecimentos para uma grande parte da população, especialmente quando dentro de uma racionalidade epidemiológica, suas repercussões em termos da reprodução das relações de gênero não podem ser desprezadas.

Observando o conjunto do material a que tivemos acesso, percebemos a intencionalidade de articular os saberes $e$ as ações clínicas (geral $e$ ginecológica-obstétrica) e epidemiológicas, em conjunto com a dimensão educativa, e podemos perceber quão específico e transformador foi o modo pelo qual valeu-se o PAISM, sobretudo, da dimensão educativa. Esse modo, porém, não se esgota nas propostas educativas internas às normas e aos manuais técnicos. Os discursos registrados no PAISM são múltiplos $e$ contraditórios, $e$ a educação aqui não significa apenas prescrições normativas a respeito do correto uso dos serviços de saúde e do correto uso e cuidado com o próprio corpo.

Os documentos analisados pertencentes ao conjunto que denominamos de educativo mostram um impacto pretendido de outra ordem, para além 
da potencialização do controle clínico, da detecção precoce de doenças e do controle de riscos à saúde, e essa ordem pretendida é a característica que o distingue de outras propostas.

É o eixo da "educação participativa" que parece ser a especificidade da integração sanitária nesse modelo particular de programação, o PAISM. Nele aparece de forma mais evidente a polaridade aqui já apontada: disseminar e ampliar a legitimidade do conhecimento técnico científico e, por outro lado, questioná-lo, ampliando as bases para a presença da mulher e para o fortalecimento de sua autodeterminação.

O PAISM publicou variado material educativo, contendo um documento com as bases para uma ação educativa, ainda em 1983: folhetos informativos, cartilhas, manuais de coordenadores de grupo de pré-natal $e$ planejamento familiar, cartazes e slides. Nos manuais são sugeridas dinâmicas para desenvolver os grupos, $e$ as cartilhas tratam de corpo, métodos contraceptivos, sexualidade, educação dos filhos, gravidez e parto. Essa variedade possui um sentido ainda mais invulgar quando verificamos que uma boa parte dessa produção foi produzida por ONGs feministas (especialmente SOS Corpo, IDAC e Fundação Carlos Chagas) em conjunto com o Ministério da Saúde. Essa inusitada e produtiva parceria não se deu sem conflitos. Uma série de cartilhas intitulada "Esse sexo que é nosso" chegou a ser distribuída e apreendida pelo Ministério da Saúde em nova conjuntura política, gerando inúmeros protestos (Brasil, 1987, p.45).

No material educativo do PAISM está a vocação mais potencialmente fecunda expressa em seu discurso. A transformação da crítica feminista ao saber/poder médico e às relações de gênero em material de difusão educativa para ser utilizado pelos serviços de saúde, além dos intensos e extensos treinamentos que tiveram lugar durante a primeira metade dos anos 80 , realizados por feministas adotando-se a chamada metodologia de trabalho feminista, tem um "impacto" coletivo imprevisível, no sentido epidemiológico. Essa metodologia, realizada por meio de oficinas e vivências, parte da experiência pessoal para a coletivização dessa experiência, capaz de despertar uma consciência coletiva, no caso, de gênero. Aplicada a profissionais de saúde da rede pública, os treinamentos representaram papel crucial na implantação do PAISM, para sensibilização das equipes para a questão de gênero e treinamento do pessoal nos novos conteúdos propostos.

A metodologia utilizada tem grande influência da pedagogia feminista, que é explicitada no texto a seguir, no qual se define o "espaço educativo" que caracterizaria essa pedagogia:

\footnotetext{
Trata-se mais de desmontar a "educação" do que estabelecer novos princípios normativos. Não importa apenas refletir sobre as contradições que emergem das relações, mas revelar o próprio movimento dos sujeitos, de forma que cada situação possa ser percebida enquanto totalidade. Um processo educativo que pretende a "integralidade da saúde" deve estar, portanto, atento às flutuações entre corpo e mente, fisiologia e sintoma, energia e anomia, saúde e doença. Nessa perspectiva, tem ainda um lugar fundamental a relação que se dá
} 


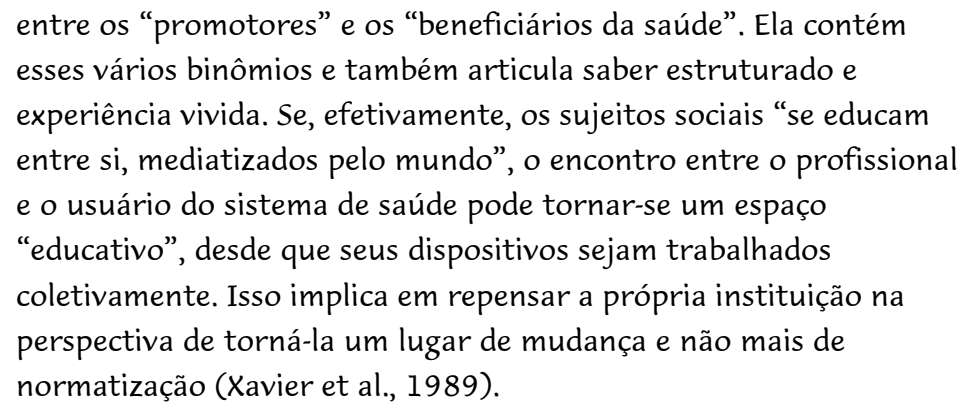

Essa proposta política, expressa por militantes feministas, ecoa na proposta educativa do PAISM, obviamente transformada pela sua incorporação institucional. Mas ainda mantém muito de sua virulência, $e$ expõe claramente suas contradições no texto intitulado "Bases para uma ação educativa" (Brasil, 1983), que pretende fornecer os princípios filosóficos e doutrinários de todo o programa.

Na primeira e segunda parte deste documento é realizada uma recuperação da relação das mulheres com o saber e a prática médica. Aqui se critica a expropriação do saber sobre o corpo feminino e a construção médica de uma mulher-mãe pelos serviços de saúde. Ao mesmo tempo, constata-se uma insuficiência desses mesmos serviços para impactar os indicadores de saúde, pois mesmo a notória priorização da atenção à gestação e ao parto não tem significado à correlata cobertura e impacto populacional que se desejaria.

O dilema entre a expropriação do saber e do controle sobre o corpo realizado pela prática médica $e$, ao mesmo tempo, as possibilidades de controle e autonomia que a tecnologia proporciona, ainda que pela tutela médica, é ressaltada quando se abordam as tecnologias contraceptivas que se tornam cada vez mais acessíveis pelos serviços de saúde.

Constatando um "fracasso" dos serviços de saúde, demonstrado pelo abandono de seguimento das mulheres e pela frustração dos profissionais de saúde, o documento propõe as bases para uma nova prática. Essa constatação embasa a exortação a uma nova forma de trabalho e de relação com a mulher e seu corpo. Falando sobre o medo que as mulheres têm do médico e do exame ginecológico, e de seus sentimentos negativos em relação ao próprio corpo, conclui-se, na primeira parte do documento:

\footnotetext{
Assim, cada vez mais, parece que as representações que as mulheres têm de seu próprio corpo, do que acontece com ele e de quem cuida dele, têm necessidade de serem faladas e conhecidas, pois podem ser desfeitas. Tem que ser permitido o necessário relaxamento e confiança em alguém que têm um saber especializado e pode colocá-lo a seu serviço, no sentido de lhe ser favorável. Pois, mais importante que oferecer conteúdos objetivos (informações sobre sexualidade, maternidade, menstruação, aborto, etc) é precisar uma forma de relação com a mulher e com o corpo dela, e isto implica num método diferente do usual nos serviços de saúde (Brasil, 1983, p.6).
}

114 Interface - Comunic, Saúde, Educ 4 
Essas bases norteariam não só as ações educativas, mas, conforme já colocado, todas as ações do PAISM, e dizem respeito a um ponto crucial para a contradição aqui apontada: as relações de poder internamente ao trabalho em saúde, tematizada pela participação:

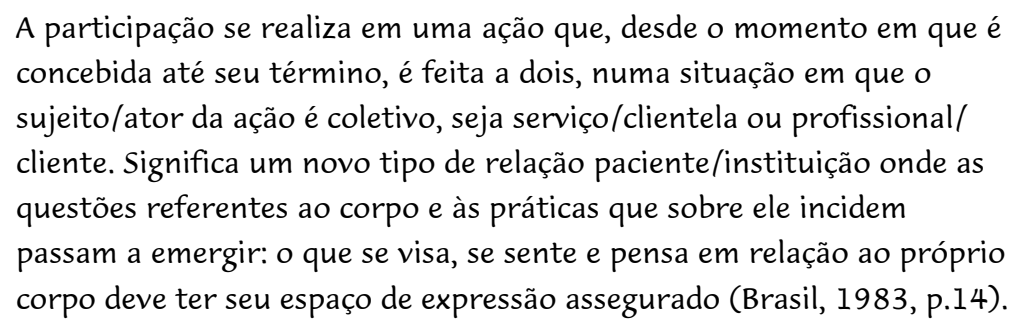

Essa proposta, básica para o PAISM, apesar de tocar no ponto crucial do poder médico, é de difícil implantação e encerra riscos. Ao estimular a fala no interior dos serviços de saúde, em situações de grande assimetria de classe, gênero e etnia, o poder médico pode acabar por simplesmente criar formas demagógicas de "participação" que terminam por quebrar as últimas resistências ao processo de medicalização, trazendo todo o mundo da vida para ser submetido aos conselhos "superiores", porque ditados com autoridade técnica e moral dos serviços de saúde, descaracterizando a proposta inicial.

A educação, proposta no PAISM em todas as atividades, tinha os grupos como seu espaço privilegiado. Os grupos podem ser organizados por qualquer profissional de saúde, sendo um espaço potencialmente mais igualitário e tendo como fundamento a metodologia "participativa".

Seja qual for a metodologia utilizada, é de fundamental importância que as práticas educativas tenham um caráter participativo, permitindo a troca de informações e experiências baseadas na vivência cotidiana das mulheres (Brasil, 1987b, p.13).

Note-se o estímulo à fala $e$ à organização de formas de trabalho para atender a demandas cada vez mais variadas, dado o estímulo ao "emergente". Deve-se lembrar aqui que o emergente possível já é por assim dizer absolutamente "contaminado" pelo saber médico. Habituado a considerar o saber científico como a verdade, o próprio saber popular é ele mesmo pleno de uma releitura do discurso médico, ou do que lhe é possível compreender desse discurso. Mescla de antigos conhecimentos com o moderno discurso científico, a percepção do corpo e suas manifestações já são permeadas fortemente pelo discurso médico, que determina inclusive as formas antecipadas de satisfação aos sofrimentos decorrentes dessas manifestações (Boltanski, 1989; Leal,1995).

A proposta educacional do PAISM buscava implodir o poder médico pelo acesso a este mesmo poder por todas as mulheres, ao mesmo tempo que esse acesso se dava por intermédio dos próprios serviços médicos, lugar de exercício desse poder. Simultaneamente, buscava resgatar uma vivência autêntica, estimular a fala daquilo que se pensa, se visa e se sente. Sendo realmente possível estimular o debate crítico acerca de concepções diversas, estimulando a reflexão emancipadora, esta visibilidade pode também ser uma forma de controle e disciplinarização dos corpos e da sexualidade (Foucault, 1993). 
Sabemos da enorme dificuldade das mulheres falarem sobre suas coisas íntimas e das dificuldades que homens e mulheres têm de discutir questões sexuais.

Esperamos que os serviços de saúde possam criar o espaço indispensável para a reflexão de questões atinentes à sexualidade humana, visando obter mais respostas que dúvidas, mais clareza que incertezas (Brasil, 1987b, p.5).

Essa clareza pretendida pelas instituições de saúde em assunto tão privado e obscuro é exercício de poder, ou seja, medicalização de relações sociais. Mas é, ao mesmo tempo, sinal de uma esperança na democratização do saber e da prática em saúde, repensando as relações de poder no interior das próprias práticas.

A proposta de educação apresentada, portanto, questiona as relações de poder instalada desde uma posição de poder, que tem que ser explicitada para ser transformada no "espaço pedagógico" proposto. No mesmo movimento, tem uma direcionalidade médico-sanitária, com objetivos estratégicos sobre a saúde feminina.

Aqui está a expressão mais fecunda das possibilidades e riscos de incorporação da questão de gênero. A mesma proposta crítica que estimula o auto-conhecimento como caminho de emancipação, cristaliza a única visão possível no espelho: A visão médica da anatomia feminina...

\section{POR QUE NÃO CONHECEMOS NOSSO CORPO?}

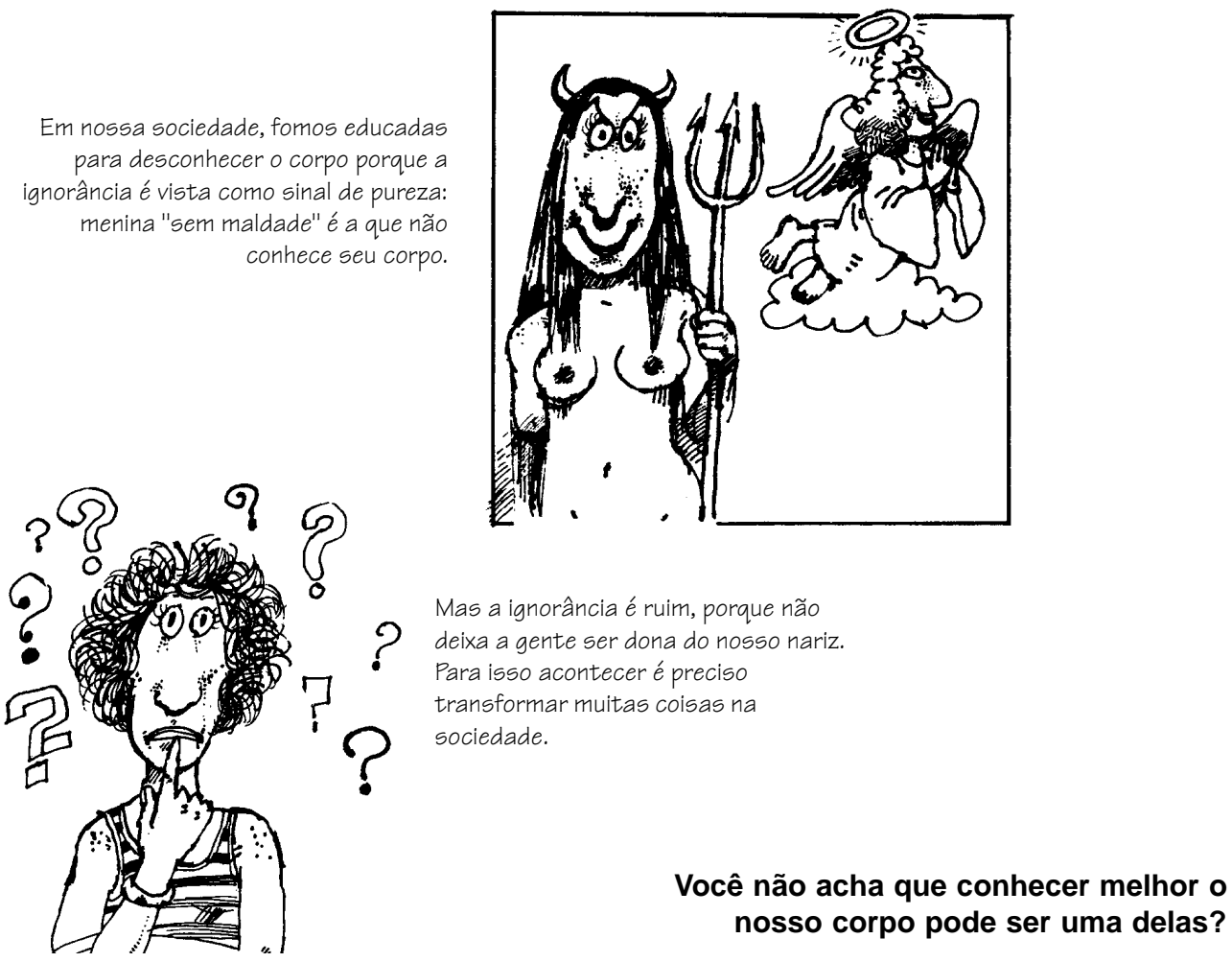

116 Interface - Comunic, Saúde, Educ 4 


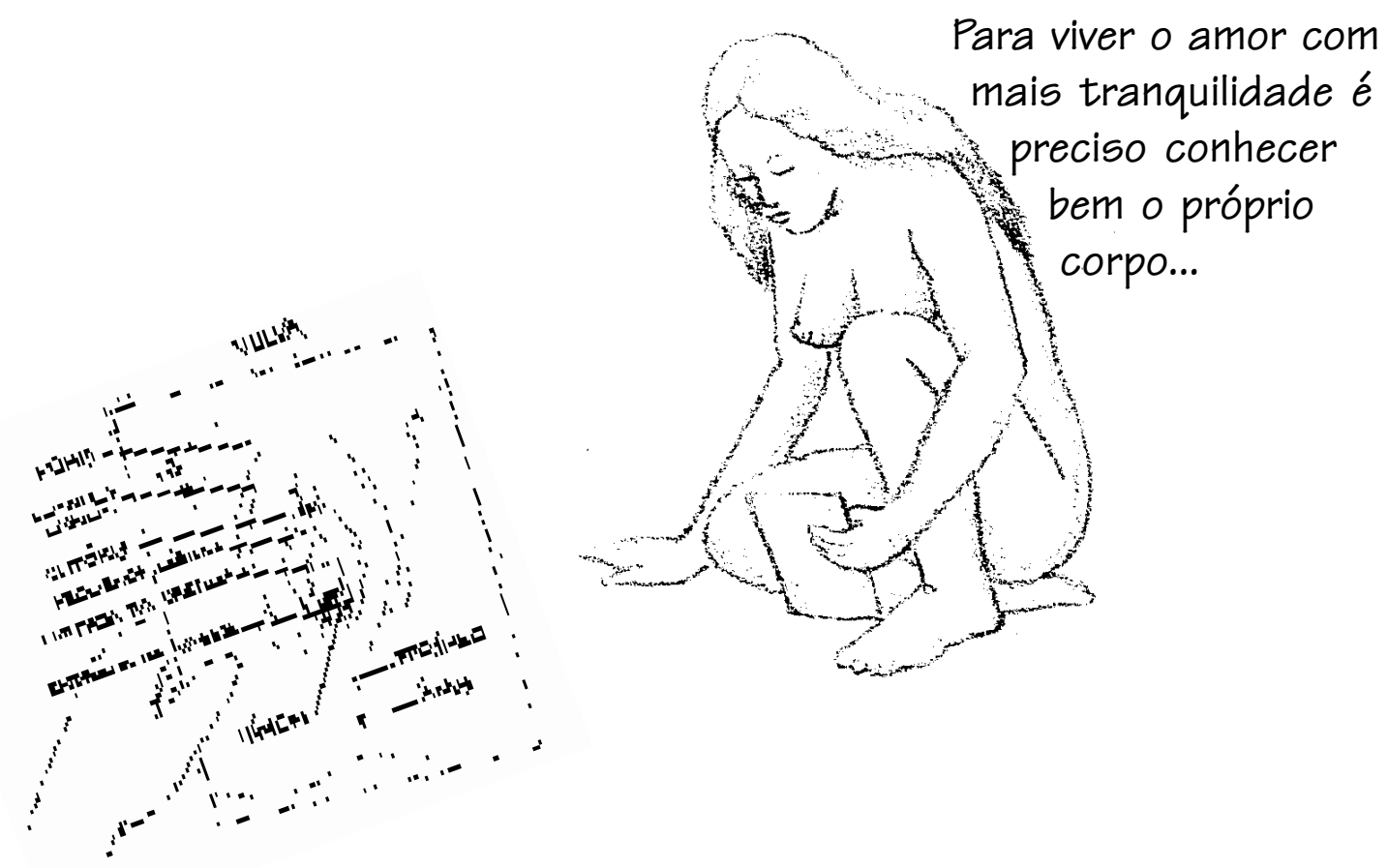

A "educação participativa", se pode ser extremamente fecunda, também corre um sério risco: sob a capa da "explicitação de relações de poder" e da igualdade entre as mulheres, ela pode tornar-se facilmente uma forma demagógica de borrar as relações de poder, tornando todas "mulheres iguais" facilitando, assim, a inculcação de modelos de feminilidade nas usuárias, quebrando mais eficazmente as resistências culturais, apesar da insistência dos documentos no respeito às diversidades regionais. Implantado em serviços nos quais a história de um outro modelo de educação (a educação sanitária) não está tão afastada no tempo, o PAISM corre o grande risco de ser reduzido a uma passagem de informações $e$ conhecimentos científicos para a mudança de comportamentos, ainda que esses novos comportamentos tenham um conteúdo moral politicamente correto. A idéia de insistir imperativamente para que as mulheres "sejam livres” está presente em muitos serviços e profissionais bem intencionados, $e$ acaba em frustração e ressentimento contra a falta de interesse e reconhecimento da população pelo esforço bem intencionado dos técnicos em saúde, reiterando preconceitos. Além disso, o convite à fala e à incorporação de novas questões para os serviços - como é o caso da sexualidade, por exemplo - pode correr o risco de reduzir essa participação a um relato de vivências tido como mera informação bruta, cuja explicação $e$ normalização é técnica e científica, reforçando o poder moral e cultural do médico.

A proposta do PAISM será tanto melhor quando os serviços, ao invés de forjarem, ou moldarem, a mulher ideal (sexualmente liberada, conhecedora de seu corpo anátomo-fisiológico e de seus direitos, ou usuária de métodos de barreira), permitirem a desconstrução da figura de mulher e a reconstrução de novas, diversas e inusitadas mulheres, que se constróem a si 
mesmas em comunhão com os outros. Para isso, é essencial que se leve em conta que a proposta do PAISM foi elaborada a partir de críticas de mulheres de classe média às atuais relações de gênero. Sua implantação radical exige que se possa ouvir as concepções e necessidades de mulheres díspares, cujas questões e concepções podem ser algumas vezes muito distantes da concepção embutida no PAISM.

Em 1988, foi realizado em Olinda um seminário de metodologia de práticas em saúde da mulher, com a participação de profissionais de saúde $e$ ativistas de grupos feministas, patrocinado pelo Conselho Nacional da Condição Feminina. Este seminário retratou uma certa desilusão e muitas dúvidas sobre o rumo da implantação do PAISM, e especialmente de sua metodologia educativa. As mulheres presentes avaliaram as dificuldades de institucionalização dessas práticas, suas origens teórico-metodológicas diversas e sua imprecisão conceitual como alguns dos principais problemas. O relatório do encontro realizou uma breve análise de conjuntura, resgatando a imensa mobilização e penetração das idéias feministas no movimento social e partidos políticos da primeira metade da década, que permitiram uma proposta como o PAISM. Detectou-se, porém, uma inflexão nesse aspecto, com a própria transição do sistema de saúde apontando para os Estados e Municípios como novos interlocutores privilegiados, ao invés do governo federal.

As mulheres presentes, em sua maioria de orientação feminista, estavam fortemente engajadas em treinamentos e capacitações dos profissionais de saúde para a implantação do PAISM.. A necessidade de pensar como estavam sendo trabalhadas as vivências e emoções colocadas tanto em termos políticos como técnicos foram levantadas. Em relação à incorporação dessa metodologia pelas instituições foi:

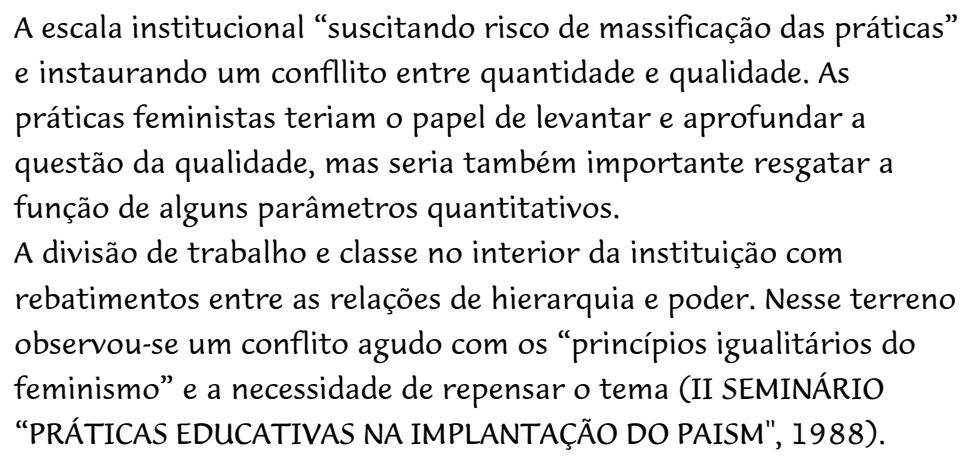

A questão das diferenças internas na hierarquia dos serviços de saúde se colocava aqui, e também "o conflito entre o conteúdo terapêutico ou educativo (político) das metodologias". A própria composição do plenário, quase exclusivamente de pessoas já identificadas com o feminismo, assim como as diversas reclamações de dificuldades e falta de prioridade no processo de implantação das práticas educativas, apontam para o relativo isolamento e secundarização desse processo no conjunto dos serviços.

Os obstáculos para a implantação radical da proposta do PAISM são realmente importantes. Além das questões já vistas aqui, as transformações 
mais recentes da prática médica, com a incorporação acentuada de novas tecnologias diagnósticas e terapêuticas, caracterizando a medicina tecnológica, fazem com que a relação intersubjetiva, na nova forma de trabalho médico, seja em grande parte dispensada pelos métodos diagnósticos, que falam pelo paciente com muito maior objetividade. (Schraiber, 1993; 1995). Na atual situação de saúde da população brasileira, se algumas poucas medidas de detecção precoce de doenças e controle de riscos fossem implementadas de maneira conseqüente já teríamos um avanço considerável em termos de indicadores de mortalidade. Mas nos atrevemos aqui a pedir ainda mais respostas porque perguntamos à educação e à prática política, que se escondem no interior da ação técnica como sua sombra perfeita, como transformar a prática, explicitando as normas envolvidas e incluindo as mulheres nas decisões sobre o próprio corpo? Qual o caminho para colocar o saber $e$ as normas em discussão, $e$ reintroduzir a mulher paciente como sujeito social? Como ver a vida social como fonte do sofrimento e prazer, dando um passo no sentido de sua transformação, e recriando as próprias normas, refazendo as relações de gênero? E qual seria a eficácia da intervenção nesse possível novo modelo?

Essas são questões colocadas para todos aqueles que tentam implementar o PAISM, em sua radicalidade. Não obstante esta dificuldade, no plano de seu discurso fica patente a penetração das questões ético-políticas trazidas pelo feminismo. Vale dizer, as questões de gênero. A possível tradução técnica desta questão - possibilidade histórica e socialmente dada - mostrou-se, como visto, perpassada por conflitos e dilemas entre o ético-político e o científico-tecnológico.

Contudo, não se pode dizer que o programa deixou de enfrentar e mostrar riscos $e$ possibilidades na incorporação das questões do poder, seja por referência às questões homem-mulher na sociedade, seja por referência às relações medicina-mulheres, no interior dos serviços de saúde.

Estas questões mostramse fecundas até hoje e continuam convidando à reflexão, como mostra com bom humor a figura ao lado, presente em material educativo do Programa.

\section{Quando a consulta termina...}

No fim da consulta devemos receber uma orientação sobre o resultado do exame ginecológico.

O médico deve explicar que exames está pedindo e para que servem. Se for indicado algum tratamento, também precisa ser bem orientado.

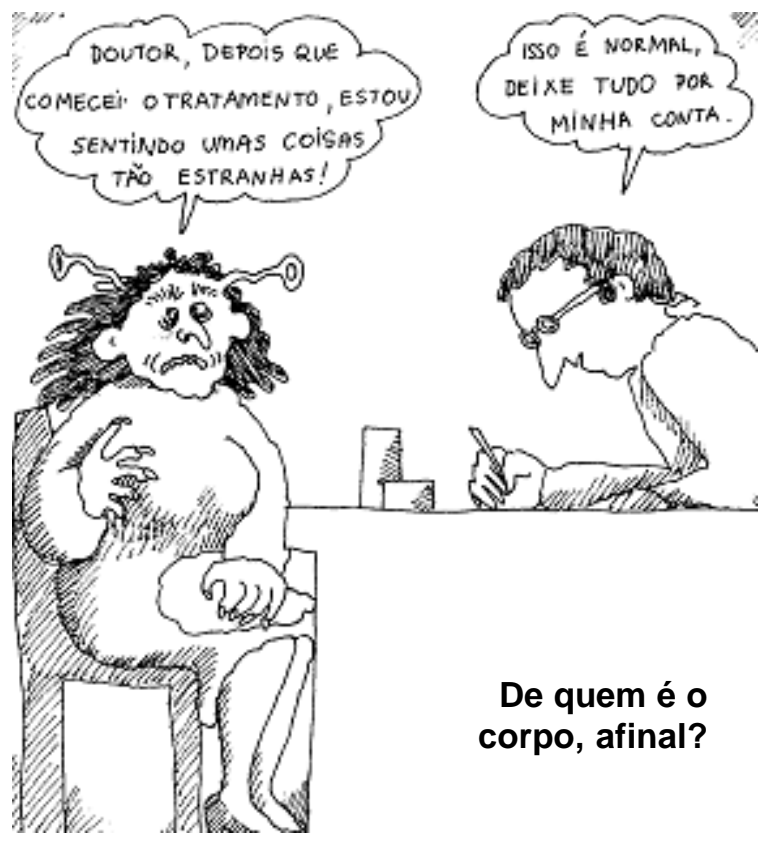

fevereiro, 1999 


\section{Referências bibliográficas}

BOLTANSKY, L. As classes sociais e o corpo. 3.ed. Rio de Janeiro: Graal, 1989.

BRASIL. Ministério da Saúde Assistência integral à saúde da mulher: bases de ação educativa. Brasília: Centro de Documentação do Ministério da Saúde, 1983.

BRASIL. Ministério da Saúde. Assistência Integral à Saúde da Mulher: bases para uma ação programática. Brasília: Centro de Documentação do Ministério da Saúde, 1984.

BRASIL. Ministério da Saúde. Conferência Nacional de Saúde e Direitos da Mulher, 10 a 13 de outubro de 1986 - Relatório Final. Brasília: Centro de documentação do Ministério da Saúde, 1987a.

BRASIL. Ministério da Saúde. Assistência ao planejamento familiar. Brasília: Centro de documentação do Ministério da Saúde, 1987b.

CORREAA, S., PETCHESKY, R. Reproductive and sexual rights: a feminist perspective. In: SEN, G.,GERMAIN, A., CHEN, L.C. Population politics reconsidered - Health, empowerment, and rights. Boston: Harvard University Press, 1994. p.107-26.

D'OLIVEIRA, A F.P.L. Gênero e violência nas práticas de saúde: contribuição ao estudo da atenção integral à saúde da mulher. São Paulo, 1996. 193p. Dissertação (Mestrado) - Faculdade de Medicina, Universidade de São Paulo.

EHRENREICH, B., ENGLISH, D. Dolencias y transtornos: politica sexual de la enfermedad. Barcelona: Dones, 1984.

FOUCAULT, M. História da sexualidade. 11.ed. Rio de Janeiro: Graal, 1993. V.1.

FUNDAÇÃO CARLOS CHAGAS - Entendendo nosso corpo. São Paulo, 1990 (Esse sexo é nosso, 1).

FUNDAÇÃO CARLOS CHAGAS - Será que eu quero ser mãe. São Paulo, 1990 (Esse sexo é nosso, 2).

FUNDAÇÃO CARLOS CHAGAS - Quando os filhos perguntam certas coisas . São Paulo, 1990 (Esse sexo é nosso, 3).

FUNDAÇÃO CARLOS CHAGAS - O exame ginecológico. São Paulo, 1990 (Esse sexo é nosso, 4).

FUNDAÇÃO CARLOS CHAGAS - Muito prazer. São Paulo, 1990 (Esse sexo é nosso, 5).

ISIS. INTERNACIONAL. Las feministas y el PAISM: la experiencia de Brasil: reflexiones $y$ acciones internacionales. Santiago del Chile: Ediciones de las mujeres, 1985. p.48-9.

LABRA, E. (Org.) Carta de Itapecirica. In: _.___-_ Mulher, Saúde e Sociedade no Brasil. Petrópolis: Vozes,1989. p.297-302.

LEAL, F.O. (Org.) Corpo e significado. Porto Alegre: Ed. da Universidade, 1995.

OSIS, M.J.D. Atenção Integral à Saúde da Mulher, o conceito e o programa: história de uma intervenção. São Paulo, 1994. 183p. Dissertação (Mestrado) - Instituto de Filosofia e Ciências Humanas, Universidade de Campinas. 
SCHRAIBER, L.B. O médico e seu trabalho: limites da liberdade. São Paulo: Hucitec, 1993.

SCHRAIBER, L.B. Desafios historicos en salud: lo individual y lo colectivo en los modelos de trabajo y asistencia. Cuad. Med. Soc., v.72, p.47-60, 1995. SEMINÁRIO "PRÁTICAS EDUCATIVAS NA IMPLANTAÇÃO DO PAISM", 2, 1995, Salvador. Salvador, Coletivo Feminista Sexualidade Saúde,1995.

TEIXEIRA, S.F.(Org) Reforma Sanitária: em busca de uma teoria. São Paulo: Cortez/Abrasco, 1989.

XAVIER, D., ÁVILA, M.B., CORRÊA S. Questões feministas para a ordem médica: o feminismo e o conceito de saúde integral. In: LABRA, M.E. (Org). Mulher, saúde e sociedade no Brasil. Petrópolis: Vozes, 1989. p.203-22.

D'OLIVEIRA, A. F. L. Salud y Educación: discusión de las relaciones de poder en la atención a la salud de la mujer. Interface - Comunicação, Saúde, Educação, v.3, n.4, 1999.

Se plantea la discusión de algunas cuestiones acerca de las acciones educativas en salud a partir de la propuesta contenida en el material del Programa de Atención Integral a la Salud de la Mujer (PAISM), publicado en la década de 80, elaborado e implementado con importante participación del movimiento feminista. Se abordan los avances traídos por la participación del movimiento social en la elaboración e implantación de políticas de salud, al lado de las dificultades asistenciales que incluso esta participación al fin y al cabo suscita. Se concluye que el programa no dejó de afrontar y demostrar los riesgos y posibilidades en la incorporación de las cuestiones del poder, sea por referencia a las cuestiones hombre-mujer en la sociedad, sea por referencia a las relaciones medicina-mujer, en el interior de las instituciones de salud, trayendo una importante cuestión ético-política al interior de las instituciones. La posible traducción técnica de esa cuestión - posibilidad histórica y socialmente planteada - se demostró, sin embargo, rozada por conflictos y dilemas entre el ético-político y el científico-tecnológico, como la dificultad de componer calidad y cantidad, saber técnico y saber popular y de cuestionar las relaciones de poder en el interior de las instituciones de gran autoridad técncica y moral en la sociedad.

PALABRAS-CLAVE: salud de la mujer, instituciones de salud, educación en salud. 


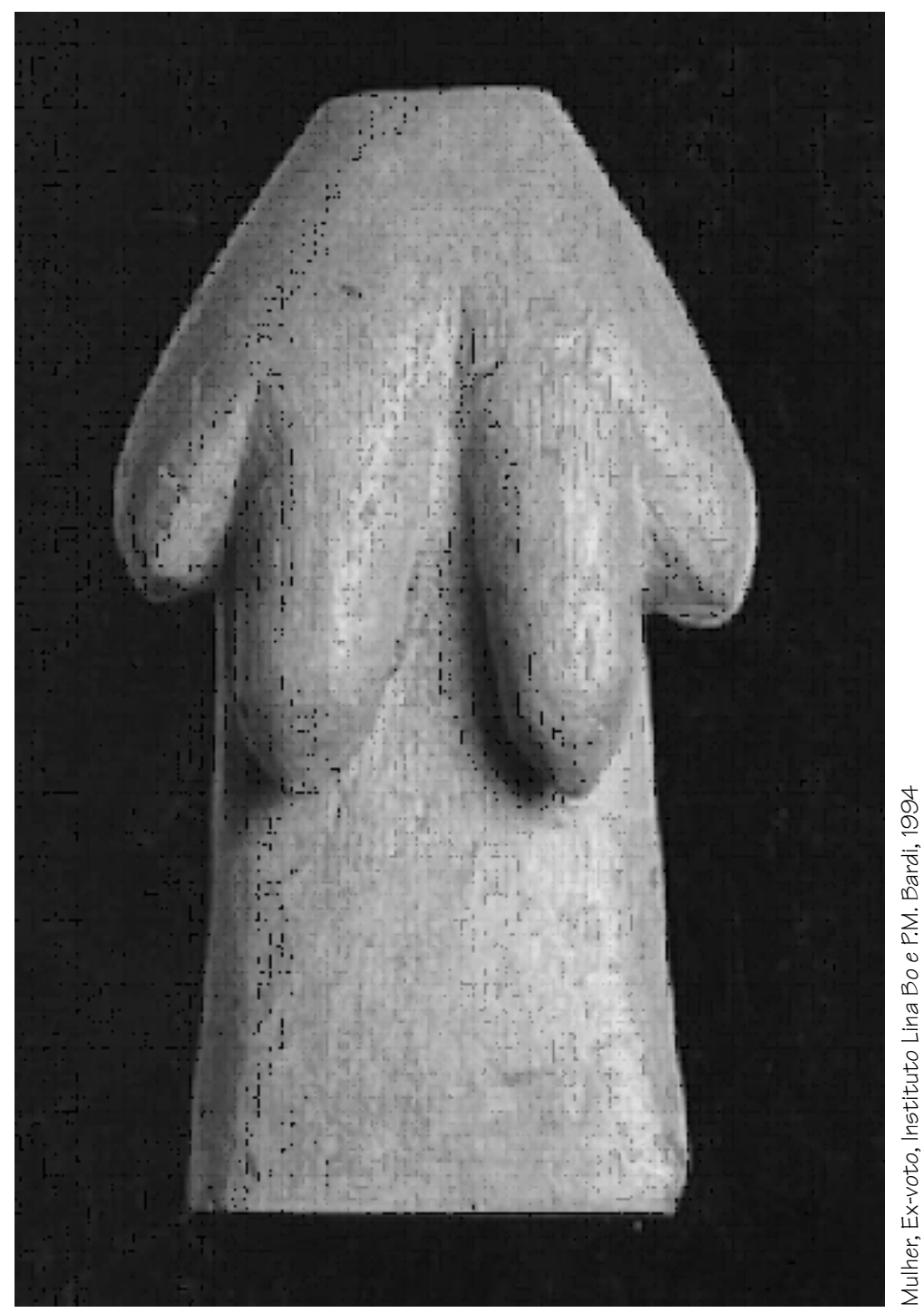

122 Interface - Comunic, Saúde, Educ 4 